\title{
Progressing Bevacizumab-Induced Diffusion Restriction Is Associated with Coagulative Necrosis Surrounded by Viable Tumor and Decreased Overall Survival in Patients with Recurrent Glioblastoma
}

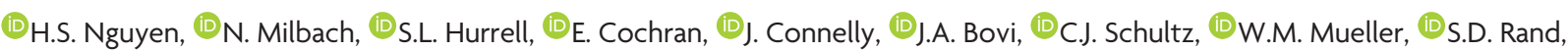
(1)K.M. Schmainda, and PP.S. LaViolette

\begin{abstract}
BACKGROUND AND PURPOSE: Patients with recurrent glioblastoma often exhibit regions of diffusion restriction following the initiation of bevacizumab therapy. Studies suggest that these regions represent either diffusion-restricted necrosis or hypercellular tumor. This study explored postmortem brain specimens and a population analysis of overall survival to determine the identity and implications of such lesions.
\end{abstract}

MATERIALS AND METHODS: Postmortem examinations were performed on 6 patients with recurrent glioblastoma on bevacizumab with progressively growing regions of diffusion restriction. ADC values were extracted from regions of both hypercellular tumor and necrosis. $A$ receiver operating characteristic analysis was performed to define optimal ADC thresholds for differentiating tissue types. A retrospective population study was also performed comparing the overall survival of 64 patients with recurrent glioblastoma treated with bevacizumab. Patients were separated into 3 groups: no diffusion restriction, diffusion restriction that appeared and progressed within 5 months of bevacizumab initiation, and delayed or stable diffusion restriction. An additional analysis was performed assessing tumor $\mathrm{O}^{6}$-methylguanine-DNAmethyltransferase methylation.

RESULTS: The optimal ADC threshold for differentiation of hypercellularity and necrosis was $0.736 \times 10^{-3} \mathrm{~mm}^{2} / \mathrm{s}$. Progressively expanding diffusion restriction was pathologically confirmed to be coagulative necrosis surrounded by viable tumor. Progressive lesions were associated with the worst overall survival, while stable lesions showed the greatest overall survival $(P<.05)$. Of the $40 \%$ of patients with $\mathrm{O}^{6}$-methylguanine-DNA-methyltransferase methylated tumors, none developed diffusion-restricted lesions.

CONCLUSIONS: Progressive diffusion-restricted lesions were pathologically confirmed to be coagulative necrosis surrounded by viable tumor and associated with decreased overall survival. Stable lesions were, however, associated with increased overall survival. All lesions were associated with $O^{6}$-methylguanine-DNA-methyltransferase unmethylated tumors.

ABBREVIATIONS: GBM = glioblastoma; MGMT = O6-methylguanine-DNA-methyltransferase; OS = overall survival

G lioblastoma $(\mathrm{GBM})$ is the most common primary brain tumor in adults, and the standard treatment of surgery, radiation, and chemotherapy is associated with a median survival of 15 months. ${ }^{1}$ At recurrence, patients typically survive only another 30

\footnotetext{
Received March 29, 2016; accepted after revision June 23.

From the Departments of Neurosurgery (H.S.N., W.M.M.), Radiology (N.M., S.L.H., S.D.R., K.M.S., P.S.L.), Pathology (E.C.), Neurology (J.C.), Radiation Oncology (J.A.B., C.J.S.), and Biophysics (K.M.S., P.S.L.), Medical College of Wisconsin, Milwaukee, Wisconsin.

This work was supported by Advancing a Healthier Wisconsin, Medical College of Wisconsin Research Affairs Committee, National Cancer Institute U01-CA176110, National Institutes of Health/National Cancer Institute R01 CA082500, American Brain Tumor Association Discovery Grant DG1600004, NIH ULITR001436, and partial funding allotted by the Medical College of Wisconsin, Department of Neurology.

Please address correspondence to Peter S. LaViolette, PhD, Department of Radiology, Medical College of Wisconsin, 8701 Watertown Plank Rd, Milwaukee, WI 53226; e-mail: plaviole@mcw.edu

- Indicates open access to non-subscribers at www.ajnr.org

http://dx.doi.org/10.3174/ajnr.A4898
}

weeks. ${ }^{2-4}$ Bevacizumab is a monoclonal antibody that selectively binds to human vascular endothelial growth factor. It is FDAapproved for recurrent $\mathrm{GBM}^{5}$ and has been shown to improve progression-free survival ${ }^{6}$ but not overall survival (OS). When given in initial treatment regimens, it has shown no benefit in OS. ${ }^{7,8}$ The permeability of the blood-brain barrier is reduced by bevacizumab; this reduction complicates the use of gadolinium contrast enhancement for the evaluation of tumor response because tumor enhancement can recede without a true antitumor response. ${ }^{9}$ As a result, the Response Assessment for Neuro-Oncology group published new suggestions that include antiangiogenic therapy. ${ }^{10}$

Other multiparametric MR imaging sequences are beginning to gain momentum in detecting infiltrative tumor and determining treatment response. Perfusion imaging methods such as DSC have been shown to be effective at measuring the response to bevacizumab. ${ }^{11-13}$ Diffusion-weighted imaging and apparent dif- 
Table 1: Patient clinical summaries for the 6 patients included in the autopsy study

\begin{tabular}{|c|c|c|c|c|c|c|c|c|c|c|}
\hline \multirow[b]{2}{*}{ Patient No. } & \multirow{2}{*}{$\begin{array}{l}\text { Last } \\
\text { MRI to } \\
\text { Death } \\
\text { (day) }\end{array}$} & \multirow{2}{*}{$\begin{array}{c}\text { Age at } \\
\text { Death } \\
\text { (yr) }\end{array}$} & \multirow[b]{2}{*}{ Tumor Type } & \multirow[b]{2}{*}{ Surgery } & \multirow[b]{2}{*}{ XRT } & \multirow[b]{2}{*}{ TMZ } & \multirow{2}{*}{$\begin{array}{l}\text { Location of } \\
\text { Focal Region } \\
\text { of Diffusion } \\
\text { Restriction }\end{array}$} & \multicolumn{3}{|c|}{ Bevacizumab (day) } \\
\hline & & & & & & & & $\begin{array}{l}\text { Before } \\
\text { Death }\end{array}$ & $\begin{array}{c}\text { Before Focal } \\
\text { Region Appears }\end{array}$ & $\begin{array}{c}\text { Between Focal } \\
\text { Region and Death }\end{array}$ \\
\hline 1 & 10 & 40 & $\begin{array}{l}\text { Grade III mixed } \\
\text { glioma }\end{array}$ & + & + & + & Corpus callosum & 44 & 34 & 10 \\
\hline 2 & 3 & 68 & GBM & + & + & + & Corona radiata & 435 & 306 & 129 \\
\hline 3 & 23 & 53 & GBM & + & + & + & Corona radiata & 85 & 34 & 51 \\
\hline 4 & 37 & 65 & GBM & + & + & + & Centrum semiovale & 343 & 264 & 79 \\
\hline 5 & 29 & 58 & GBM & + & + & + & Corpus callosum & 827 & 728 & 99 \\
\hline 6 & 62 & 42 & GBM & + & + & + & Centrum semiovale & 700 & 534 & 166 \\
\hline
\end{tabular}

Note:-XRT indicates radiation therapy; TMZ, temozolomide; +, yes.

\section{Shape Preserving Patient Specific Brain Fixation Mold}
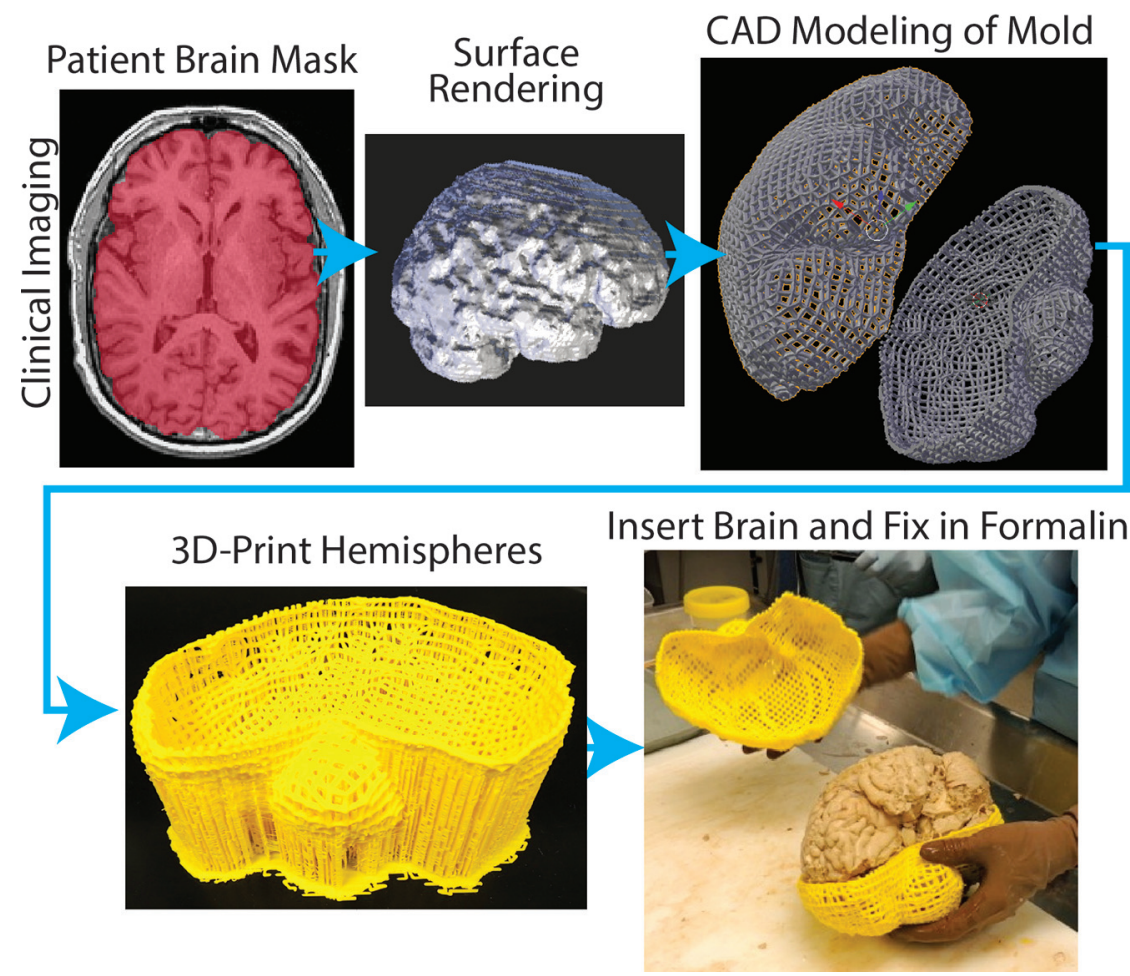

FIG 1. Demonstration of the creation of a patient-specific brain mold for minimizing tissue distortion during fixation. The patient's MR imaging is used to generate a brain mask, which is then used as a guide for generating the mold in 3D modeling software. Molds are then 3D-printed in plastic.
This generally results in high diffusion and consequent hyperintensity on $\mathrm{ADC}$ images. Coagulative necrosis, however, is grossly firm with microscopic "ghostly" cells, in which only the outline and cytoplasm remain but all organelles are absent. $^{31}$

This study explored regions of diffusion restriction following bevacizumab therapy in 2 ways: First, we analyzed tissue samples from patients at postmortem to pathologically confirm tumor cellularity or coagulative necrosis. Next, we assessed a patient population to determine the effect that these lesions have on OS. We then performed a subanalysis on tumor $O^{6}$-methylguanine-DNA-methyltransferase (MGMT) methylation, a predictor of overall survival. $^{23,32}$

\section{MATERIALS AND METHODS Patient Population}

The brains from 6 patients with recurrent GBM and regions of focal diffusion restriction (while on bevacizumab therapy) were assessed at postmortem as part of an internal review board-compliant study (PRO17446). Table 1 provides a fusion coefficient temozolomide maps measure the free diffusion of water in tissue. ADC has been shown to inversely correlate with tumor cellularity in glioma, ${ }^{14,15}$ and ADC difference maps or functional diffusion maps are predictive of response to chemotherapy, ${ }^{16,17}$ radiation therapy, ${ }^{18}$ and bevacizumab. ${ }^{19,20}$

Some patients, when given bevacizumab, develop focal regions of diffusion restriction. These lesions, when stable, have been shown to be associated with increased survival. ${ }^{21}$ Conflicting studies have shown these regions to be either diffusion-restricted necrosis or hypercellular tumor. ${ }^{21-28}$ One recent article reported regions of both within ADC-FLAIR mismatch (ie, diffusion restriction within fluid-attenuated inversion recovery hyperintensity) and found that diffusion-restricted necrosis had significantly lower ADC values compared with hypercellular tumor. ${ }^{29,30}$

Glioblastomas are typically associated with liquefactive necrosis, characterized by its purulent appearance and liquid texture. brief clinical history of each patient. The cohort consisted of 1 woman and 5 men, with a mean age of 54 years (range, 39.9-67.8 years). All patients had surgical resection, concurrent radiation, and temozolomide therapy and bevacizumab at tumor recurrence. The mean period between the initiation of bevacizumab therapy and the appearance of focal regions of diffusion restriction was 316.6 days (range, 34-728 days); the mean period between initiation of bevacizumab therapy and death was 405.6 days (range, 44-827 days); and the mean period between the appearance of a focal diffusion-restricted region and death was 89 days (range, 10-166 days).

\section{Imaging}

The patients were clinically imaged on either a 1.5T Symphony or Espree (Siemens, Erlangen, Germany) or a 1.5T Optima or 3T Discovery (GE Healthcare, Milwaukee, Wisconsin) scanner by 


\section{Patient Specific MRI Oriented Brain Slicing Mold}

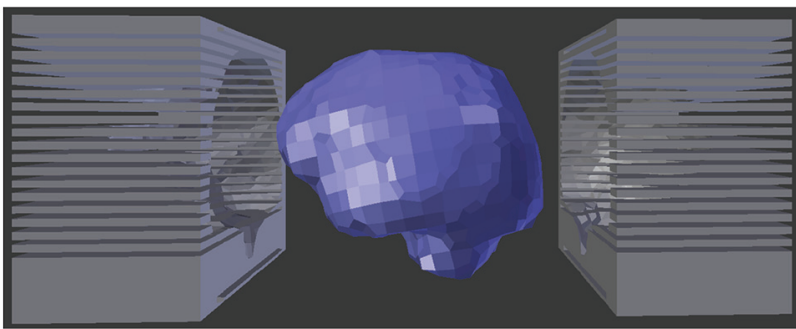

3D-Printed Mold with Brain

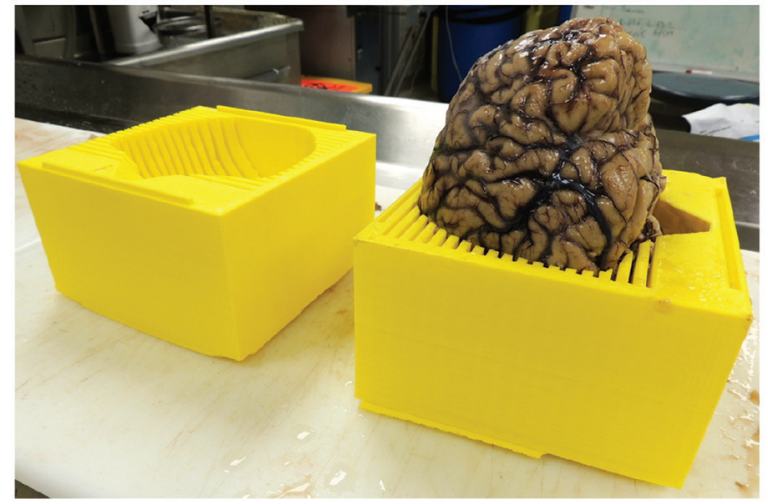

Example Slice Co-Registered with MRI

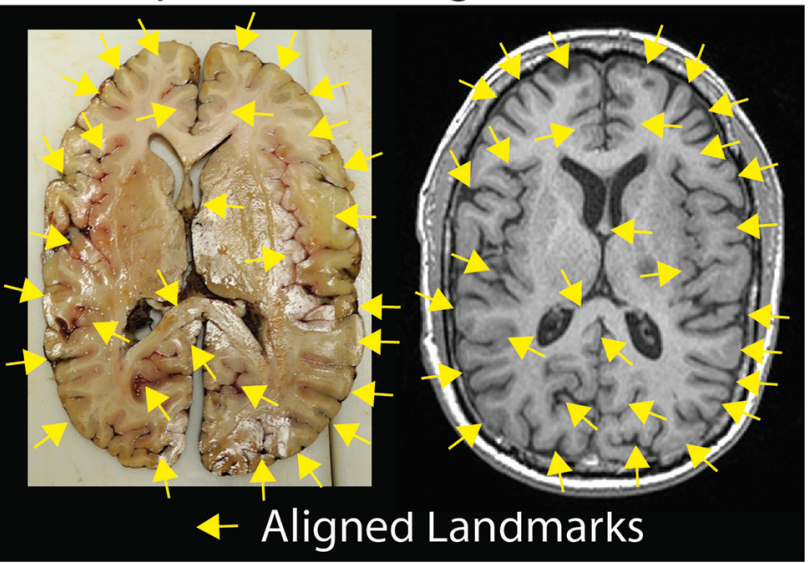

FIG 2. Demonstration of the use of a custom 3D-printed slicing jig for sectioning the brain in the same axial orientation as the imaging. Shown on the lower right are examples of gyri and sulci that align well with the imaging (yellow arrows).

using DWI ( $b=0$ and 1000), T1 pre- and postgadolinium, and T2 FLAIR. ADC maps were calculated from DWI by using Analysis of Functional Neuro Images software (AFNI; http://afni.nimh.nih. gov/afni) and the equation $\mathrm{ADC}=(1 / 1000) \times \ln (\mathrm{B} 0 / \mathrm{B} 1000)$. Imaging, including the ADC maps, was coregistered to the T1weighted image by using the FMRIB Linear Image Registration Tool (FLIRT; http://www.fmrib.ox.ac.uk/).

\section{Histology Processing and ADC Correlation}

The tissue was processed as previously published, ${ }^{29}$ with some modifications. To prevent tissue distortion during brain fixation, for 4 of the 6 postmortem cases, at the time of removal, we placed brains in patient-specific, MR imaging-derived, 3D-printed

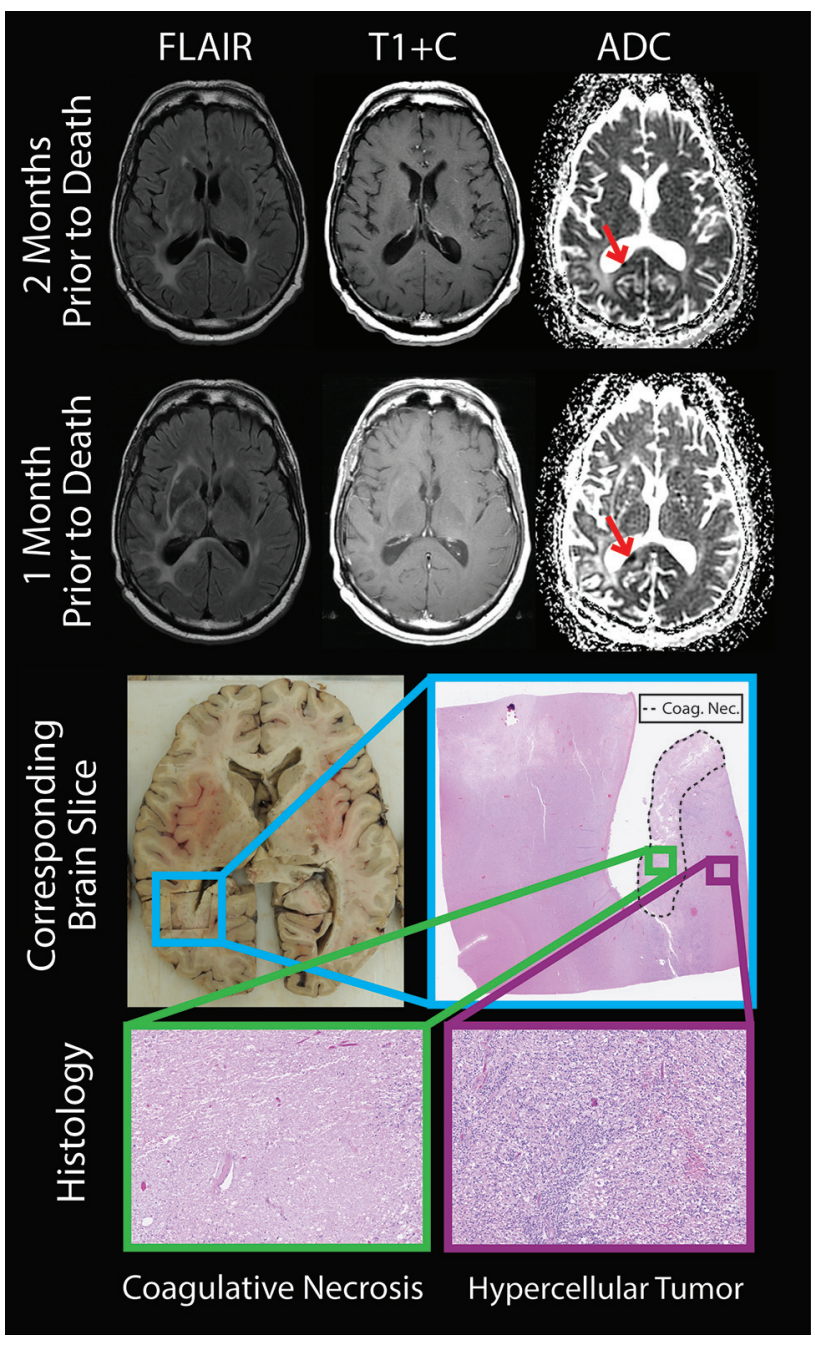

FIG 3. The brain section and corresponding imaging from a representative patient. The diffusion-restricted lesion (red arrows) was growing between the 2 imaging sessions, shown 2 months and 1 month before death. Histology revealed coagulative necrosis surrounded by viable hypercellular tumor (lower section). $\mathrm{T} 1+\mathrm{C}$ indicates $\mathrm{Tl}+$ gadolinium contrast.

molds (Fig 1). ${ }^{33}$ Molds were generated by using open-source software, including the FSL Brain Extraction Tool (http://fsl.fmrib. ox.ac.uk/fsl/fslwiki/BET) for generating a brain mask, 3D Slicer (www.slicer.org) for wrapping a surface model around the mask, and Blender (www.blender.org) for creating the final mold design. Each was then printed by using a MakerBot Replicator 3Dprinter (fifth-generation) (www.makerbot.com). Postmortem slicing of the brains was done by using a universal slicing jig for 2 patients and a customized 3D-printed slicing jig for 4 patients (Fig 2). Each jig was similarly designed in Blender by using the patient's imaging as described above and printed by using the same $3 \mathrm{D}$ printer. Tissue specimens were taken from regions of diffusion restriction as defined by radiologic criteria. Samples were paraffinembedded, hematoxylin-eosin-stained, and digitized for interpretation and quantification. Each sample was graded to differentiate necrotic regions from viable tumor, and ROIs were manually drawn on each sample to differentiate the 2 tissue types. The digitized histology was then segmented to highlight individual cells ${ }^{29}$ and coregistered to the imaging by using custom software and AJNR Am J Neuroradiol 37:2201-08 Dec 2016 www.ajnr.org 
Table 2: Demographics for the retrospective bevacizumab study

\begin{tabular}{|c|c|c|c|}
\hline & $\begin{array}{c}\text { NDR }(n=45),{ }^{a} \text { (Meth } \\
[n=8] / \text { Unmeth }[n=10])\end{array}$ & $\begin{array}{l}\text { StDR }(n=10))^{b} \\
\text { (Unmeth [n=7]) }\end{array}$ & $\begin{array}{c}\operatorname{PrDR}(n=9),{ }^{c} \\
\text { (Unmeth }[n=4])\end{array}$ \\
\hline Age at death (yr) (mean) (SD) & $55(13)(58 / 63)$ & $55(11)(55)$ & $52(8)(58)$ \\
\hline \multicolumn{4}{|l|}{ Sex } \\
\hline Male & $23(4 / 4)$ & $6(4)$ & $8(4)$ \\
\hline Female & $22(4 / 6)$ & $4(3)$ & $1(0)$ \\
\hline $\begin{array}{l}\text { Days between bevacizumab } \\
\text { initiation and death } \\
\text { (median) (lower/upper } \mathrm{Cl})\end{array}$ & $256(213-298)(524-352)$ & $516(197-835)(484)$ & $183(125-241)(252)$ \\
\hline $\begin{array}{l}\text { Recurrences/progression } \\
\text { (median) (range) }\end{array}$ & $2(1-5)(2.5 / 2.2)$ & $2(1-5)(2.57)$ & $2(1-3)(1.5)$ \\
\hline \multicolumn{4}{|l|}{ Initial pathology } \\
\hline Grade II & $5(1 / 1)$ & $1(1)$ & $0(0)$ \\
\hline Grade III & $2(0 / 1)$ & $2(2)$ & $1(0)$ \\
\hline GBM & $38(7 / 8)$ & $7(4)$ & $8(4)$ \\
\hline \multicolumn{4}{|l|}{ Therapeutic regimen } \\
\hline $\begin{array}{c}\text { Surgery }+ \text { XRT/TMZ }+ \\
\text { adjuvant TMZ }\end{array}$ & $45(8 / 10)$ & $10(7)$ & $9(4)$ \\
\hline Reoperation & $22(2 / 5)$ & $6(4)$ & $2(0)$ \\
\hline Bevacizumab & $45(8 / 10)$ & $10(7)$ & $9(4)$ \\
\hline Stopped? ${ }^{\mathrm{a}}$ & $10(1 / 3)$ & $3(1)$ & $1(0)$ \\
\hline Irinotecan & $6(0)$ & $2(0)$ & $3(0)$ \\
\hline Isotretinoin & $15(2 / 3)$ & $2(2)$ & $1(0)$ \\
\hline CCNU/BCNU & $8(3 / 1)$ & $2(2)$ & $3(2)$ \\
\hline Interferon & $2(0)$ & $0(0)$ & $0(0)$ \\
\hline Optune $^{d}$ TTF & $0(0)$ & $1(1)$ & $0(0)$ \\
\hline PLDR & $12(5 / 4)$ & $5(4)$ & $3(2)$ \\
\hline
\end{tabular}

Note:-PLDR indicates pulsed low-dose rate radiation; NDR, no diffusion restriction; StDR, stable diffusion restriction; PrDR, progressive diffusion restriction; TTF, tumor treating fields; Meth, methylation; Unmeth, no methylation; CCNU/ $B C N U$, carmustine/lomustine; XRT, radiation therapy: TMZ, temozolomide.

a Bevacizumab was stopped for further surgery (for resection, $n=5$; for infection, $n=1$; for shunting, $n=1$; for hemorrhage, $n=1$; buttock abscess, $n=1$; and hip fracture, $n=1$ ).

${ }^{\mathrm{b}}$ Bevacizumab was stopped for neutropenia/thrombocytopenia $(n=1)$, fatigue $(n=1)$, and hemorrhage $(n=1)$.

${ }^{\mathrm{C}}$ Bevacizumab was stopped for further surgery (resection, $n=1$ ).

${ }^{\mathrm{d}}$ Novocure, Portsmouth, New Hampshire.

previously published methods. ${ }^{29}$ Figure 3 shows a representative patient in whom the target region of diffusion restriction as defined by imaging is compared with the matching brain section and sample location. The ROIs defining necrotic areas were downsampled to the MR imaging resolution, and ADC values were then extracted from regions of diffusion-restricted necrosis and areas classified as hypercellular. We performed a receiver operating characteristic analysis, iteratively adjusting ADC cutoff values until a maximal area under the curve was obtained for differentiating diffusion-restricted necrosis from hypercellularity for each patient.

Sixty-four patients who underwent bevacizumab treatment for recurrent GBM were retrospectively assessed by using our clinical PACS system to determine whether diffusion-restricted lesions developed following treatment onset (Table 2). Two reviewers (H.S.N. and P.S.L.) determined by consensus which patients developed diffusion-restricted lesions, which were then verified by a board-certified neuroradiologist (S.D.R.). It is the standard practice in our neuro-oncology clinic for patients to undergo MR imaging each month following the onset of bevacizumab therapy for the first 6 months. Follow-up imaging intervals are then extended at the discretion of our neuro-oncologist.

Patients were separated into 3 groups: 1) no diffusion restriction $(n=45), 2)$ new diffusion restriction that appeared and progressively grew within 5 months of bevacizumab initiation $(n=9)$, and 3 ) delayed onset (the lesion appeared $>5$ months after bevacizumab initiation) or new diffusion restriction $(<3$ months postbevacizumab) that remained stable for $>3$ months (onset and progression totaling $>5$ months) $(n=10)$. Diffusionrestricted lesion progression or growth was assessed qualitatively and verified by our neuroradiologist (S.D.R.). Progression was defined by any increase in lesion size beyond the initial lesion appearance (see Fig 4 for examples). Conditions of patients with multiple lesions were classified as progressive if any lesion was progressing, and conditions in patients with lesions decreasing in size were classified as stable. The OS after initiation of bevacizumab therapy within each group was then compared with Kaplan-Meier curves and a logrank test via SPSS 22 (IBM, Armonk, New York). An additional survival analysis was performed separating patients on the basis of MGMT methylation status of initial tumor samples.

\section{RESULTS}

Regions of diffusion-restricted necrosis had significantly lower ADC values than nearby hypercellularity (Table 3 ). The ADC threshold that best differentiated these tissue types was $0.736 \times$ $10^{-3} \mathrm{~mm}^{2} / \mathrm{s}$, corresponding to an average area under the curve of 0.816 (Table 3). The average ADC value within diffusion-restricted necrosis was $0.663 \times$ $10^{-3} \mathrm{~mm}^{2} / \mathrm{s}$, while the average ADC within regions of hypercellularity was $0.925 \times 10^{-3} \mathrm{~mm}^{2} / \mathrm{s}$. In 5 of the 6 patients, the diffusion-restricted necrosis was progressively growing at the time of the patient's final scan. For these 6 patients, the necrotic regions were surrounded by viable hypercellular nonenhancing tumor. The patient without progressively growing diffusion restriction had recurrent tumor elsewhere, not directly adjacent to the diffusion-restricted lesion.

Figure 5 shows the survival curves comparing no diffusion restriction, progressive diffusion restriction, and stable diffusion restriction, in which patients with stable diffusion restriction had a significantly greater OS than the group with no diffusion restriction $(P<.05)$, while the progressive diffusion restriction group had significantly lower OS than the stable diffusion restriction group $(P<.05)$ (Fig 5, upper section). Although initially stable, at the time of death all diffusionrestricted lesions were progressing in the group with stable diffusion restriction.

Of the 64 retrospective patients, 37 were tested for MGMT methylation. Tumor samples from 8 of 18 patients in the nodiffusion-restriction group were found to be MGMT methylated $(40 \%)$. None of the patients with methylation developed diffusion-restricted lesions. The patients without methylation, when separated by diffusion-restriction status, showed the same survival trend as that in the overall population analysis (Fig 5, middle section). There was no survival difference between patients with unmethylated stable diffusion restriction compared with the patients with methylation and no diffusion restriction (Fig 5 , lower section). 


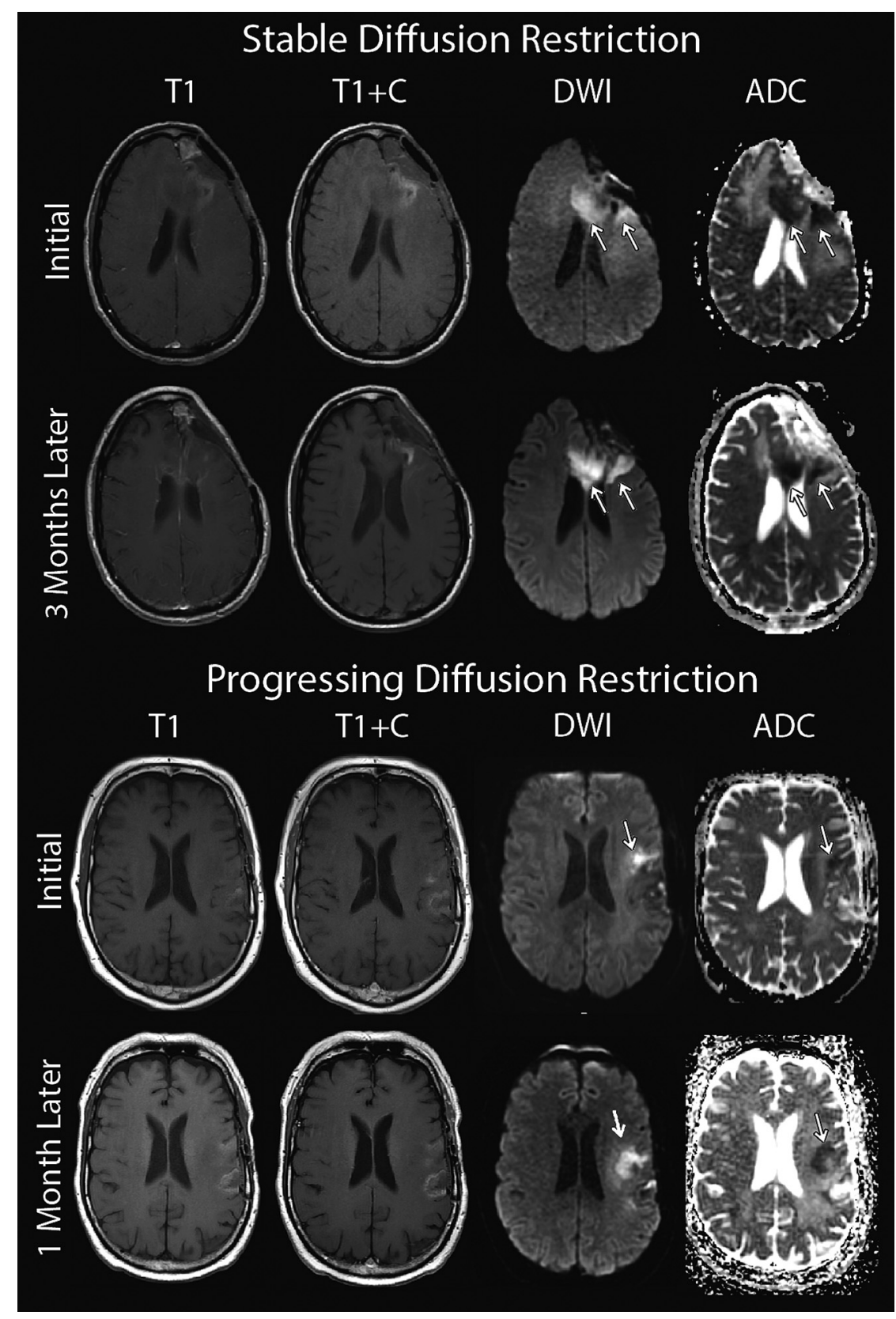

FIG 4. Examples of stable and progressive diffusion-restricted lesions occurring following the onset of bevacizumab treatment.

Table 3: Summary of the ADC values within regions of DRN and hypercellularity

\begin{tabular}{llccclc}
$\begin{array}{c}\text { Patient } \\
\text { No. }\end{array}$ & $\begin{array}{c}\text { ADC } \\
\text { DRN }\end{array}$ & $\begin{array}{c}\text { DRN } \\
\text { Nvox }\end{array}$ & $\begin{array}{c}\text { ADC } \\
\text { HypCel }\end{array}$ & $\begin{array}{c}\text { HypCel } \\
\text { Nvox }\end{array}$ & $\begin{array}{c}\text { Scanner } \\
\text { Svima }\end{array}$ & $\begin{array}{c}\text { Field } \\
\text { Strength }\end{array}$ \\
\hline 1 & 0.578 & 142 & 0.694 & 256 & Optima $^{\mathrm{a}}$ & $1.5 \mathrm{~T}$ \\
2 & 0.552 & 122 & 1.000 & 143 & Symphony $^{\mathrm{b}}$ & $1.5 \mathrm{~T}$ \\
3 & 0.622 & 88 & 1.076 & 72 & Optima $^{\mathrm{a}}$ & $1.5 \mathrm{~T}$ \\
4 & 0.786 & 237 & 1.170 & 950 & Discovery $^{\mathrm{a}}$ & $3 \mathrm{~T}$ \\
5 & 0.699 & 96 & 0.775 & 584 & Symphony $^{\mathrm{b}}$ & $1.5 \mathrm{~T}$ \\
6 & 0.743 & 121 & 0.838 & 129 & Espree $^{\mathrm{b}}$ & $1.5 \mathrm{~T}$ \\
Average & 0.663 & 134 & 0.926 & 356 & & \\
\hline
\end{tabular}

Note:-DRN indicates diffusion restricted necrosis; Nvox, number of voxels; HypCel, hypercellular.

${ }^{a}$ GE Healthcare, Milwaukee, Wisconsin.

b Siemens, Erlangen, Germany.

\section{DISCUSSION}

This study explored focal regions of diffusion restriction following bevacizumab treatment. At postmortem, we found that pro- gressively growing lesions were predominantly coagulative necrotic tissue surrounded by viable nonenhancing hypercellular tumor. Analysis of ADC values showed that a cutoff of $0.736 \times$ $10^{-3} \mathrm{~mm}^{2} / \mathrm{s}$ best separated diffusion-restricted necrosis and viable hypercellular tumor. We also found that patients with stable diffusion-restricted lesions had significantly greater OS, while those with progressing diffusion restriction had shorter OS than those who never developed lesions. We also found that all the patients who developed diffusionrestricted lesions had unmethylated MGMT and that the patients with stable diffusion restriction showed a survival benefit similar to that of those with MGMT methylation with no diffusion restriction.

Several recent studies have explored these diffusion-restricted lesions. Gupta et $\mathrm{al}^{24}$ noted that diffusion restriction preceded the development of enhancing tumor in a subset of patients with glioblastoma, independent of bevacizumab therapy; this finding suggested that such restriction represented hypercellular tumor. A case report from Gerstner et $\mathrm{al}^{25}$ showed pathologically confirmed, nonenhancing tumor colocalized with diffusion restriction. Pope et $\mathrm{al}^{34}$ investigated low ADC values through histogram analysis and agreed with the conclusion that low values indicated areas of hypercellularity. Other studies, however, have hypothesized that these regions could not correspond to tumor because not all conditions of patients progressed. ${ }^{35,36}$ They instead hypothesized that these regions would most likely be chronic hypoxia and necrosis. ${ }^{36}$

Population studies examining these lesions have likewise found contradictory results. Studies by Mong et $\mathrm{al}^{21}$ and Bähr et $\mathrm{al}^{37}$ found that patients who demonstrated stable diffusion restriction following bevacizumab treatment had increased overall survival, again suggesting that the lesions were not viable tumor. The study of Mong et $\mathrm{al}^{21}$ confirmed gelatinous necrosis in 1 patient through biopsy. In addition, 5 patients from the literature with sampled biopsies and 2 brain donations demonstrated necrosis within these focal regions. ${ }^{21,26,28,37,38}$ Zhang et $\mathrm{al}^{23}$ however, found that survival was dependent on the size of the focal lesion.

AJNR Am J Neuroradiol 37:2201-08 Dec 2016 www.ajnr.org 
Diffusion Restriction Survival Analysis
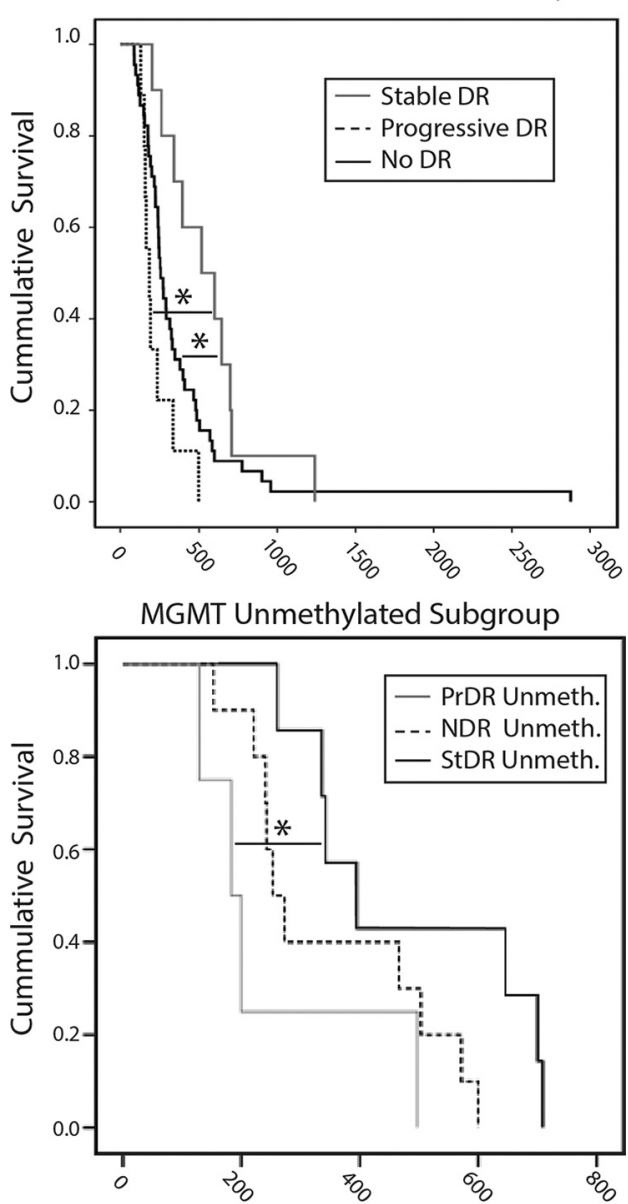

MGMT Meth. NDR vs. Unmeth. StDR

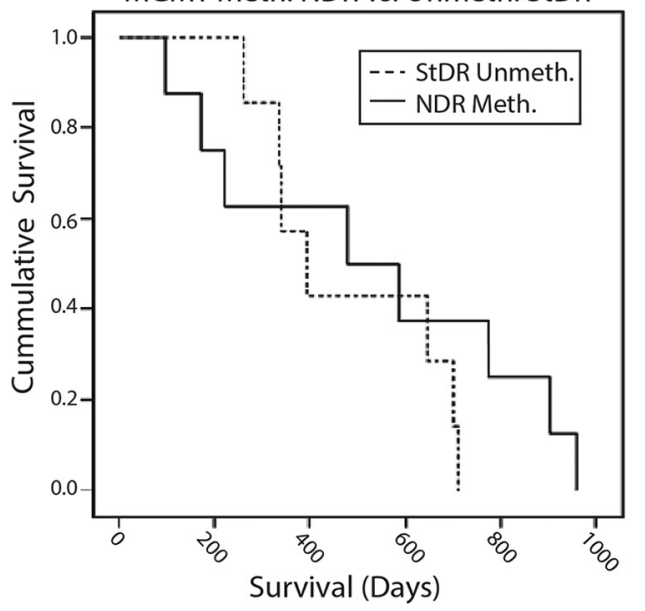

FIG 5. Survival analyses comparing groups. Upper Section, Overall survival is significantly greater in patients with stable diffusion restriction compared with those with no diffusion restriction $(P<.05)$. OS is significantly lower in patients with progressive diffusion restriction compared with those with stable diffusion restriction $(P<.05)$. Middle Section, Unmethylated tumors show survival trends similar to those in the overall population, in which patients with stable diffusion restriction survived longer than those with no diffusion restriction and progressive diffusion restriction $(P<.05)$. Lower Section, Patients with unmethylated stable diffusion restriction show survival similar to those with no diffusion-restriction methylation. DR indicates diffusion restriction; PrDR, progressive diffusion restriction; NDR, no diffusion restriction; StDR, stable diffusion restriction; Meth, methylation; Unmeth, no methylation.
Our postmortem findings suggest that regions of diffusion restriction themselves are diffusion-restricted coagulative necrosis. Most important, in 5 of 6 patients, the lesions were progressing at the time of death and were surrounded by viable nonenhancing hypercellular tumor. These tumorous regions are deceptively invisible on contrast-enhanced T1-weighted imaging. This finding may clarify previous reports; if viable tumor was found it would have been reported preferentially to necrosis and given the nature of biopsies, samples could be associated with the incorrect location just adjacent to the actual dark spot.

Diffusion restriction has gained traction as an alternative marker to assess treatment response and tumor progression. Prior glioma studies have found an inverse correlation between ADC and cellularity, tumor grade, and Ki-67 proliferation indices. ${ }^{24,34}$ Increasing $\mathrm{ADC}$ values have been associated with a reduction in cellularity attributed to effective treatment, edema, and/or radiation necrosis. ${ }^{15,34}$ Our study finds, however, that coagulative necrosis, which is rare in the brain, is associated with extremely low diffusion values. Two other studies found similar ADC values within diffusion-restricted necrosis of $0.71^{29}$ and $0.63 \times$ $10^{-3} \mathrm{~mm}^{2} / \mathrm{s} .{ }^{35}$ One study examined the change in ADC values with the onset of bevacizumab treatment for predictive power in survival rates. ${ }^{19}$ The authors found that smaller negative changes were more indicative of OS than larger negative changes. We suggest that this finding is because a small drop in ADC value indicates hypercellularity, whereas a large change indicates diffusion-restricted necrosis.

Our results showed that diffusion-restricted lesions could indicate either decreased or increased OS, depending on lesion progression. In our population study, we determined that patients with stable diffusion restriction had a significantly greater OS than those with no diffusion restriction, while patients with progressive diffusion restriction had significantly lower OS than those with both stable diffusion restriction and no diffusion restriction. Patients with stable diffusion restriction may predominantly exhibit necrosis in diffusion-restricted regions, leading to greater OS, while patients with progressive diffusion restriction may exhibit less necrosis surrounded by greater expanding tumor, leading to shortened survival.

Diffusion restriction is typically seen along the ventricles and corpus callosum in qualitative analyses of patients with GBM. ${ }^{21,31}$ This finding was true in most of our patients, with diffusion restriction occurring along the lateral ventricles or corpus callosum.

Methylation has been shown to be a strong indicator of survival in patients with GBM. ${ }^{39}$ We found that patients with unmethylated stable diffusion restriction on bevacizumab had similar survival compared with those with MGMT methylation with no diffusion restriction. Further investigation is needed to understand the inverse correlation between diffusion restriction and MGMT methylation.

The mechanism behind diffusion-restricted necrosis has been postulated in prior literature. In a case report, Jeyaretna et $\mathrm{al}^{38}$ hypothesized that bevacizumab exacerbated radiation necrosis, which may lead to the development of focal regions of coagulative necrosis. Others hypothesized that such regions result from bevacizumab-induced chronic hypoxia. ${ }^{26}$ These regions were detectable as early as 4 weeks after the initiation of bevacizumab and were maintained for up to 80 weeks. ${ }^{26}$ In addition, they have been predominantly observed along white matter tracts, particularly the corpus callosum and corona radiata. ${ }^{24}$ Similarly, our cohort of 
patients also exhibited a wide time range between the initiation of bevacizumab therapy and the appearance of a focal region of diffusion restriction. Moreover, all regions, except 1, were within white matter.

There are several sources of potential error in this study. First, our patients were not scanned in the same machine, which could produce differences in our ADC threshold calculation. Although $\mathrm{ADC}$ is quantitative, magnet strength and other factors contribute to heterogeneity in ADC values. Coregistration of the histology and imaging is also a source of potential error. We minimized tissue distortion and sectioned the brains according to imaging; however, small errors could have occurred during the slicing. Further research is necessary to determine the accuracy of our brainslicing technology. In addition, because the CSF drains following brain removal, this phenomenon causes the ventricles to shrink, with irreversible distortion compared with in vivo imaging.

Future studies should look at using our calculated ADC threshold for mapping necrotic-versus-hypercellular tumor. This would then allow quantitative monitoring of tumor growth on a voxelwise basis. Future studies should also look at including additional multiparametric MR images that may potentially help differentiate tumor, such as blood-volume maps.

\section{CONCLUSIONS}

We pathologically confirmed that progressively expanding diffusion restriction in patients undergoing bevacizumab treatment indicates coagulative necrosis surrounded by viable hypercellular tumor. We also determined an optimal ADC cutoff for differentiating diffusion-restricted necrosis from hypercellular tumor. In the population analysis, patients with progressively growing regions of diffusion restriction have decreased overall survival, suggesting that the lesions themselves, when expanding, are necrosis surrounded by viable tumor. Patients with stable lesions, however, showed increased OS over the group with no diffusion restriction. Further research is necessary to establish the biologic basis for bevacizumab causing these lesions.

\section{ACKNOWLEDGMENTS}

We thank the patients and their families who graciously chose to participate in this study.

Disclosures: Jennifer Connelly_UNRELATED: Board Membership: Novocure, ${ }^{*}$ Comments: Advisory Board. Christopher Schultz-UNRELATED: Board Membership: Prism Imaging (Scientific Advisory Board, unpaid); Grants/Grants Pending: Elekta AB, ${ }^{*}$ Comments: MR Linac Consortium research support; Travel/Accommodations/ Meeting Expenses Unrelated to Activities Listed: Elekta AB.* Kathleen M. Schmainda—RELATED: Grant: National Institutes of Health*; UNRELATED: Grants/ Grants Pending: National Institutes of Health*; Other: Imaging Biometrics, Comments: ownership interest in a company that develops MRI postprocessing software. *Money paid to the institution.

\section{REFERENCES}

1. Stupp R, Mason WP, van den Bent MJ, et al; European Organisation for Research and Treatment of Cancer Brain Tumor and Radiotherapy Groups, National Cancer Institute of Canada Clinical Trials Group. Radiotherapy plus concomitant and adjuvant temozolomide for glioblastoma. $N$ Engl J Med 2005;352:987-96 CrossRef Medline

2. Iwamoto FM, Abrey LE, Beal K, et al. Patterns of relapse and prognosis after bevacizumab failure in recurrent glioblastoma. Neurology 2009;73:1200-06 CrossRef Medline

3. Wong ET, Hess KR, Gleason MJ, et al. Outcomes and prognostic factors in recurrent glioma patients enrolled onto phase II clinical trials. J Clin Oncol 1999;17:2572-78 Medline

4. Lamborn KR, Yung WK, Chang SM, et al; North American Brain Tumor Consortium. Progression-free survival: an important end point in evaluating therapy for recurrent high-grade gliomas. Neuro Oncol 2008;10:162-70 CrossRef Medline

5. Cohen MH, Shen YL, Keegan P, et al. FDA drug approval summary: bevacizumab (Avastin) as treatment of recurrent glioblastoma multiforme. Oncologist 2009;14:1131-38 CrossRef Medline

6. Friedman HS, Prados MD, Wen PY, et al. Bevacizumab alone and in combination with irinotecan in recurrent glioblastoma. J Clin Oncol 2009;27:4733-40 CrossRef Medline

7. Chinot OL, Wick W, Mason W, et al. Bevacizumab plus radiotherapy-temozolomide for newly diagnosed glioblastoma. $N$ Engl J Med 2014;370:709-22 CrossRef Medline

8. Gilbert MR, Dignam JJ, Armstrong TS, et al. A randomized trial of bevacizumab for newly diagnosed glioblastoma. N Engl J Med 2014; 370:699-708 CrossRef Medline

9. de Groot JF, Fuller G, Kumar AJ, et al. Tumor invasion after treatment of glioblastoma with bevacizumab: radiographic and pathologic correlation in humans and mice. Neuro Oncol 2010;12:233-42 CrossRef Medline

10. Wen PY, Macdonald DR, Reardon DA, et al. Updated response assessment criteria for high-grade gliomas: Response Assessment in Neuro-Oncology Working Group. J Clin Oncol 2010;28:1963-72 CrossRef Medline

11. LaViolette PS, Cohen AD, Prah MA, et al. Vascular change measured with independent component analysis of dynamic susceptibility contrast MRI predicts bevacizumab response in high-grade glioma. Neuro Oncol 2013;15:442-50 CrossRef Medline

12. Schmainda KM, Prah M, Connelly J, et al. Dynamic-susceptibility contrast agent MRI measures of relative cerebral blood volume predict response to bevacizumab in recurrent high-grade glioma. Neuro Oncol 2014;16:880-88 CrossRef Medline

13. Sawlani RN, Raizer J, Horowitz SW, et al. Glioblastoma: a method for predicting response to antiangiogenic chemotherapy by using MR perfusion imaging-pilot study. Radiology 2010;255:622-28 CrossRef Medline

14. Sugahara T, Korogi $\mathrm{Y}$, Kochi M, et al. Usefulness of diffusionweighted MRI with echo-planar technique in the evaluation of cellularity in gliomas. J Magn Reson Imaging 1999;9:53-60 Medline

15. Ellingson BM, Malkin MG, Rand SD, et al. Validation of functional diffusion maps (fDMs) as a biomarker for human glioma cellularity. J Magn Reson Imaging 2010;31:538-48 CrossRef Medline

16. Moffat BA, Chenevert TL, Lawrence TS, et al. Functional diffusion map: a noninvasive MRI biomarker for early stratification of clinical brain tumor response. Proc Natl Acad Sci U S A 2005;102:5524-29 CrossRef Medline

17. Hamstra DA, Galbán CJ, Meyer CR, et al. Functional diffusion map as an early imaging biomarker for high-grade glioma: correlation with conventional radiologic response and overall survival. J Clin Oncol 2008;26:3387-94 CrossRef Medline

18. Ellingson BM, Cloughesy TF, Zaw T, et al. Functional diffusion maps (fDMs) evaluated before and after radiochemotherapy predict progression-free and overall survival in newly diagnosed glioblastoma. Neuro Oncol 2012;14:333-43 CrossRef Medline

19. Ellingson BM, Cloughesy TF, Lai A, et al. Graded functional diffusion map-defined characteristics of apparent diffusion coefficients predict overall survival in recurrent glioblastoma treated with bevacizumab. Neuro Oncol 2011;13:1151-61 CrossRef Medline

20. Ellingson BM, Kim E, Woodworth DC, et al. Diffusion MRI quality control and functional diffusion map results in ACRIN 6677/RTOG 0625: a multicenter, randomized, phase II trial of bevacizumab and chemotherapy in recurrent glioblastoma. Int J Oncol 2015;46: 1883-92 CrossRef Medline

21. Mong S, Ellingson BM, Nghiemphu PL, et al. Persistent diffusionrestricted lesions in bevacizumab-treated malignant gliomas are 
associated with improved survival compared with matched controls. AJNR Am J Neuroradiol 2012;33:1763-70 CrossRef Medline

22. Hwang EJ, Cha Y, Lee AL, et al. Early response evaluation for recurrent high grade gliomas treated with bevacizumab: a volumetric analysis using diffusion-weighted imaging. J Neurooncol 2013;112: 427-35 CrossRef Medline

23. Zhang M, Gulotta B, Thomas A, et al. Large-volume low apparent diffusion coefficient lesions predict poor survival in bevacizumabtreated glioblastoma patients. Neuro Oncol 2016;18:735-43 CrossRef Medline

24. Gupta A, Young RJ, Karimi S, et al. Isolated diffusion restriction precedes the development of enhancing tumor in a subset of patients with glioblastoma. AJNR Am J Neuroradiol 2011;32:1301-06 CrossRef Medline

25. Gerstner ER, Frosch MP, Batchelor TT. Diffusion magnetic resonance imaging detects pathologically confirmed, nonenhancing tumor progression in a patient with recurrent glioblastoma receiving bevacizumab. J Clin Oncol 2010;28:e91-93 CrossRef Medline

26. Rieger J, Bähr O, Müller K, et al. Bevacizumab-induced diffusionrestricted lesions in malignant glioma patients. J Neurooncol 2010; 99:49-56 CrossRef Medline

27. Rieger J, Bähr O, Ronellenfitsch MW, et al. Bevacizumab-induced diffusion restriction in patients with glioma: tumor progression or surrogate marker of hypoxia? J Clin Oncol 2010;28:e477; author reply e478 CrossRef Medline

28. Farid N, Almeida-Freitas DB, White NS, et al. Restriction-spectrum imaging of bevacizumab-related necrosis in a patient with GBM. Front Oncol 2013;3:258 CrossRef Medline

29. LaViolette PS, Mickevicius NJ, Cochran EJ, et al. Precise ex vivo histological validation of heightened cellularity and diffusion-restricted necrosis in regions of dark apparent diffusion coefficient in 7 cases of high-grade glioma. Neuro Oncol 2014;16:1599-606 CrossRef Medline
30. Farid N, Almeida-Freitas DB, White NS, et al. Combining diffusion and perfusion differentiates tumor from bevacizumab-related imaging abnormality (bria). J Neurooncol 2014;120:539-46 CrossRef Medline

31. Robbins SL, Cotran RS, Kumar V. Robbins and Cotran Pathologic Basis of Disease. Philadelphia: Saunders/Elsevier; 2010

32. Hegi ME, Diserens AC, Gorlia T, et al. MGMT gene silencing and benefit from temozolomide in glioblastoma. N Engl J Med 2005;352: 997-1003 CrossRef Medline

33. Pellatt B, Mickevicius NJ, Cochran EJ, et al. 3D-printed MRI-based custom brain molds for minimizing tissue distortion and precisely slicing tissue for co-registration with clinically acquired MRI in glioma patients. Neuro-Oncology 2014;16(suppl 5):v152 CrossRef

34. Pope WB, Kim HJ, Huo J, et al. Recurrent glioblastoma multiforme: ADC histogram analysis predicts response to bevacizumab treatment. Radiology 2009;252:182-89 CrossRef Medline

35. Reiger J, Bähr O, Müller K, et al. Bevacizumab-induced diffusionrestricted lesions in malignant glioma patients. J Neurooncol 2010; 99:49-56 CrossRef Medline

36. Rahman R, Hamdan A, Zweifler R, et al. Histogram analysis of apparent diffusion coefficient within enhancing and nonenhancing tumor volumes in recurrent glioblastoma patients treated with bevacizumab. J Neurooncol 2014;119:149-58 CrossRef Medline

37. Bähr $\mathrm{O}$, Harter $\mathrm{P}$, Weise $\mathrm{L}$, et al. Sustained focal antitumor activity of bevacizumab in recurrent glioblastoma. Neurology 2014;83:227-34 CrossRef Medline

38. Jeyaretna DS, Curry WT Jr, Batchelor TT, et al. Exacerbation of cerebral radiation necrosis by bevacizumab. J Clin Oncol 2011;29: e159-62 CrossRef Medline

39. Rivera AL, Pelloski CE, Gilbert MR, et al. MGMT promoter methylation is predictive of response to radiotherapy and prognostic in the absence of adjuvant alkylating chemotherapy for glioblastoma. Neuro Oncol 2010;12:116-21 CrossRef Medline 